\title{
Physician assistants - a missed opportunity in the British Army?
}

\author{
TPLaH Brown, H Becker
}

\section{Introduction}

The severe shortage of medical specialists in the Defence Medical Services has been highlighted recently, including the continued loss of trained clinical staff at a rate of more than 700 per year (1). The British Medical Association estimates that it would be more than 10 years before replacement staff could be adequately trained to work unsupervised, particularly with the drive towards consultant delivered care. Although reliance is placed on the reserve forces, volunteer strength is only $65 \%$ of required establishment and the Ministry of Defence do not expect 'that Reserve establishment targets will be reached for at least the next couple of years' (2).

These difficulties are by no means limited to the United Kingdom, and the United States developed a non-physician health care provider called the Physician Assistant $(\mathrm{PA})$ in response to a similar problem. Although designed to fill a shortfall of medical staff in armed forces, the popularity of PAs has grown in the United States, and they now practice in both civilian and military health care.

A difference between the British and American medical systems is the blurred boundary between medical practitioners and professions allied to medicine (PAMS). In the USA it is particularly true of the physician assistant, which has no equivalent counterpart in the United Kingdom. In the eventuality of British Forces being deployed with US allies, it is probable that British medical and nursing staff will find themselves working in parallel with physician assistants from the United States. The aim of this article is to introduce physician assistants to readers who may find themselves in such a situation, and try and dispel attempts at categorizing PAs as 'consultant nurse', 'super CMT' or 'semidoctor'. PAs are none of these things and a combination of all of them!

Key words: Physician assistant, army

\section{History}

In the late 1960s the physicians draft was abolished, creating a shortage of doctors for front line combat units. To address the shortcoming Dr. Eugene Stead, of the Duke University Medical Center in North Carolina, developed a non-physician health care provider called the physician assistant.
The first class was selected in 1965 fron Navy corpsmen with considerable medicas training during their military service an\& during the Vietnam conflict, but with nop medical experience in civilian practice $\overrightarrow{0}$ Between 1973 \& 1977 eight classes of PAs. were trained with the intention 0 क employing them as a temporary stop gap foo physician shortages. However, they wer enormously successful with commandin officers who requested further PAs in fronN line units. The courses were, thereforec, recommenced in 1979 and have continue $\$$ ever since.

\section{Education \& training}

The curriculum developed for Dr Stead PA programme was in part based on the fast-track training of doctors that wa necessary during World War II. The emphasis was on intensely practical issues of medical practice rather than 'minutiae and this remains the backbone of $\mathrm{P} P 0$ programmes. PAs are educated in a fashio: designed to complement medica $\$$ practitioner training and facilitate an eas $\vec{\Phi}$ working relationship. A typical $P \$$ education programme is usually $25-2$ 䎹 months in length and is taught b physicians, PAs, and basic scientists. Entra stipulations for most courses requir applicants to have previous health caro experience (usually 4 years as a nurs@ CMT or paramedic) and some forma educational qualification; typically Bachelor's degree. The first year provides broad grounding in medical principles wit a focus on their clinical applicabilityo Teaching consists of classroom and laboratory instruction in basic medic sciences amounting to 1600 hours oves twelve months. In the second year, students receive hands on clinical training through $\mathbb{R}^{2}$ series of clerkships in a variety of inpatien: and outpatient settings. Rotations include general medicine, general practice, surgerj产 paediatrics, obstetrics and gynaecology an accident and emergency medicinep Physician assistant students complete o융 average over 2000 hours of supervise $\$$ clinical practice prior to graduation, whic is probably more than most UK medicar graduates.

\section{Accreditation}

In the United States there are currently 
more than 120 courses leading to accreditation, but increasing interest in PAs has led to establishment of many new programmes. Upon completion of a course physician assistants must pass a National Certification Examination. To maintain their certification, PAs are required to $l o g$ 100 hours of continuing medical education (CME) every two years and re-sit the National Certification Examination every six years, regardless of their area of practice. In addition, a number of postgraduate courses have been developed in medical and surgical specialties.

\section{Functions \& responsibilities}

In the United States, PAs are licensed to practice medicine only with physician supervision. As part of their responsibilities PAs undertake patient admission, diagnose and treat illnesses, order and interpret tests, counsel on preventive health care, assist in theatre and, in most parts of the United States, write prescriptions (47 out of 52 states). A PA may be employed in any setting authorized by the supervising doctor, including, but not limited to, GP surgeries, hospitals, mobile surgical units, patient's homes, nursing homes and other institutional settings such as prisons. Although over $50 \%$ work in primary care, $20 \%$ work in surgical disciplines where they assist in theatre in the same manner as a surgical trainee. Surgical PAs provide postoperative care, managing patients on the intensive care unit or ward. They are trained to insert and remove vascular access and monitoring devices (including Swan-Ganz catheters, CVP lines, arterial lines, Foley catheters); insert and remove drains (including intra-thoracic drainage catheters); regulate the pharmacological needs of the patient (including analgesics, antibiotics, anticoagulants, insulin, etc.); remove temporary pacemaker wires, casts, sutures or skin clips in addition to other tasks delegated by the surgeon. Surgical PAs also oversee dictation of discharge summaries and arrange out patient followup appointments.

\section{Regulation}

The American Academy of Physician Assistants (AAPA) is responsible for collecting and auditing data to track the growth and changes in the profession. These audits are published annually and are available on the Academy's web site (http://www.aapa.org). It is responsible for ensuring that professional standards are maintained, but has no executive authority. A separate body, the National Commission on Certification of Physician Assistants (NCCPA) has certain censorial powers including the ability to revoke or suspend the PAs national certification. Without national certification, the PA's license may be suspended or revoked depending on the State in which the PA is licensed. The St 7 Re medical board can require a PA to atte counseling as needed and impose correctse measures. In common with medical practitioners, PAs are required to Be licensed by the State in which they wodk. Even if nationally certified, a State cain refuse permission to practice in comm with the rules governing medieal practitioners.

\section{Malpractice}

Information from the National Practitioner Data Bank (NPDB) reveals that PAs incu $\overrightarrow{D a}$ low rate of malpractice judgments a $\vec{a}$ d reduce the risk of malpractice liabilify. Although PAs are supervised in the sarde way as non-consultant grade junior doct क्षे in the UK, they remain liable for their actions. Even in the case of being covered ty their employer's insurance, they may \&e liable to the employer who has pad compensation to the claimant. The Healph Care Quality Improvement Act (1986) requires that all malpractice paymergs made on behalf of any clinician (doctors $\underset{\Phi}{\Phi}$ PAs) must be reported to the NPDB, wiph the details of who was at fault. The mogt recent data suggests that 272.8 physiciąs and 11.7 PAs exist for every 100,000 people, and 23.4 physicians for every Pa All things being equal, physician related negligence recorded by the NPDB shougd be 23.4 times that involving PAs. In realigy, the number of physician related claims 420 times that involving PAs. Since the daina bank began collecting statistics in 1990 בa total of 100,750 claims were settled againg physicians, with an average paid claim $\$ 188,773$. During the same period, a to of 240 claims were settled on behalf of PAs, with an average claim of $\$ 83,625(3,4)$. The reasons for this difference are uncler although effective communication wigh patients is demonstrable in avoidance $\overbrace{0 \mathrm{f}}$ litigation and PA education focuses strongy on this element of training $(5,6)$. It has also been suggested that employing a PA coufd reduce the risk of malpractice judgments allowing the supervising physician concentrate on more demanding elemergs of patient care (7). Employing a PA reduces waiting time and provides patients wi greater attention, which enhances patiegt rapport and satisfaction.

The findings of a Hurley Medical Cent㠃r (HMC) research project, recently published in the Fournal of Trauma, re-enforce toge value of physician assistants (8). T $\overrightarrow{\text { pe }}$ Michigan-based medical center hథ्ष employed PAs as members of the surgia staff since 1985. In 1994, HMC began formal trauma program staffed by surgeoßs and PAs, who worked as surgical residents. In the programmes' first two years there wh a $43 \%$ reduction in the time taken for acute 
trauma cases to reach theatre and $51 \%$ reduction in the transfer time to an intensive care unit. As a result, the length of stay in intensive care for head injured patients decreased by a third. All trauma surgeons reported that the clinical assessments conducted by PAs were consistent with their own findings and rated PA surgical assistants as either very good or excellent.

\section{Physician Assistants in the US Army}

The US Army has its own PA School, based at Fort Sam Houston, in San Antonio, Texas. At present there are 517 PAs in the US army, which equates to one for each combat unit. As the ethos is of an intensely practical occupation, PAs are sent from Certification straight to front line units rather that being 'interned' in a hospital. A mentor system operates, to ensure that newly qualified PAs are not left in situations that may leave them feeling isolated or out of their depth.

US Army PAs differ greatly from those in the Navy \& Air Force and also their civilian counterparts, in that they are based with their battalion, compared to a more hospital and primary care role for those in the other forces. There are no US Army PAs in field or general hospitals, except for those in training. In war time, US Army PAs are based at the regimental aid post where they provide BATLS-type care, but have the ability to move forward if needed. In peace time however, they have a primary health care role at battalion level. They are responsible for the day to day health care of the soldiers and their families, act as teachers for battlefield trauma training and are responsible for ensuring adequate medical supplies are available. As such they are a fully accepted part of the health care system and their work load is considerable; for example, over a 3 months period the 18 US Army PAs stationed in Germany saw 16,250 patients.

\section{Conclusions}

Physician assistants are not likely to develop rapidly in the United Kingdom. At present there is no legislative framework that would ${ }_{\supset \supset}^{C}$ allow PAs to practice and changes to the Medical Act would be required. In addition, with a drive towards consultant delivered, rather than consultant led care, PAs may not be accepted, or viewed with suspicion, $\bigcirc$ by the British public.

In the United States however, PAs are a? tried and tested part of medical practice for $\overrightarrow{\bar{\omega}}$ the last 30 years. They are used extensivelyo throughout the Armed Forces of our majoro NATO partner, and future deployment willos. inevitably lead to contact between British $\frac{\mathbb{}}{\square}$ Forces and physician assistants. Althoughe perceived as a threat by some doctors, thereare proven advantages in employing theseindividuals, and PAs have been embraced asw a solution to chronic shortages of suitably qualified, motivated, medical practitioners. 亏ै

\section{Acknowledgement}

We would like to thank LTC Louis H Smitli III, Chief, Physician Assistant Section, US' Army Medical Command, for his advice in preparing this paper.

This work was made possible in part by a $\overrightarrow{0}$ Award from the Drummond Foundation.

\section{References}

1. Campbell M, Simpson G. Emergency in the Defence Medical Services RUSI Newsbrief 2001;21(1):9-12.

2. Defence Select Committee Third Report, sessio 96-97, page iv, para 7 .

3. Ryser J. Claims rate low: PAs seen as asset if liability crisis. Am Med News 1976; April 26:1,11-1유

4. The National Practitioner Data Bank ResearcQ File of September 30, 1997, as maintained by th $\vec{\delta}$ Division of Quality Assurance, Bureau of Healt Professions, Health Resources and Services Administration, US Department of Health an: Human Services

5. Frankel RM. Communicating with patient Research shows it makes a difference. $A A P$ 霖 NEWS 1995;16(2):8.

6. Lester GW, Smith SG. Listening and talking patients. A remedy for malpractice suits? West Med 1993;158(3):268-272.

7. Shapiro RS, Simpson DE, Lawrence SL, et al. survey of sued and non sued physicians and suirf patients. Arch Intern Med 1989;149(10):219@ 2196.

8. Miller W, Riehl E, Napier M, Barber K, Dabideco $\mathrm{H}$. Use of physician assistants as surgery/traum house staff at an American College of Surgeone verified Level II trauma center. I Trauma 199 Feb;44(2):372-6 